\title{
Meter per Second Squared
}

National Cancer Institute

\section{Source}

National Cancer Institute. Meter per Second Squared. NCI Thesaurus. Code C42572.

Meter per second squared is a SI unit of acceleration. 